\title{
Sünger Filtre İle Çamur Yoğunlaştırmada Ozonun Etkisi ve Maliyet Analizi
}

\author{
Orhan GÖKYAY ${ }^{1}$, Samet ÇIRAK ${ }^{2}$ \\ ${ }^{1}$ Marmara Üniversitesi, Mühendislik Fakültesi, Çevre Mühendisliği Bölümü, 34672, Kadıköy /İSTANBUL \\ ${ }^{2}$ Marmara Üniversitesi, Fen Bilimleri Enstitüsü, Çevre Mühendisliği Bölümü, 34672, Kadıköy /İSTANBUL
}

\section{Özet}

Atık sulardan kaynaklanan çamurların uzaklaştırılması atıksu mühendisliği sahasının en zor ve en pahalı problemi olmaya devam etmektedir. Atıksu arıtma tesisleri, kullanılan sisteme göre ön çöktürme çamuru, aktif çamur, kimyasal çamur veya anaerobik çamur gibi farklı çamurlar üretmektedir. Bu artık çamurlar, uzaklaştırılmadan önce hacimlerinin azaltılması ve stabilize hale getirilmesi gibi işlemlere tabi tutulmak zorundadırlar. Bunun için genellikle kullanılan yöntemler koşullandırmayla birleştirilmiş yoğunlaştırma ve susuzlaştırmadır.

Çamur yoğunlaştırma ve susuzlaştırma ya büyük bir ilk yatırım ya da büyük bir yüzey alan gerektirmektedir. Bundan başka, mekanik ekipmanlar susuzlaştırma işleminden önce polimer takviyesine ihtiyaç duymaktadırlar. Kullanılan polimerlerin masrafı mekanik yoğunlaştırma ve susuzlaştırmayı ekonomik olmaktan uzaklaştırmaktadır.

Bu çalışmada sünger filtre ile çamur yoğunlaştırma ve susuzlaştırmada ozonun etkisi araştırılmış, ayrıca maliyet analizi yapılmıştır. Polimer ilavesi ile daha yoğun ve daha susuz bir çamur elde etmek mümkündür ve bunun ilk yatırım maliyeti ozonlama sistemine göre daha düşüktür. Fakat ozonun benzer etkiyi gösterdiği anlaşılmış olup, 11 yıl sonra çamuru ozonlamanın daha ekonomik olacağı anlaşılmıştır.

Anahtar Kelimeler: Çamur yoğunlaştırma, Sünger Filtre, Çamur Ozonlama, Çamur Susuzlaştırma, Ozonlama Maliyeti

\begin{abstract}
The ultimate disposal of wastewater sludge (biosolids) continues to be one of the most difficult and expensive problems in the field of wastewater engineering. Wastewater treatment plants generate different sludges, like primary settled sludge, waste activated sludge, chemical sludge and anaerobic sludge, according to their operating systems. These excess sludges have to be managed by reducing their volume and stabilizing them before their ultimate disposal. Generally used volume reduction methods are thickening and dewatering that are usually coupled with conditioning.

Sludge thickening and dewatering require either a big capital investment or a big surface area. Moreover, most of the mechanical dewatering technologies use polymers to condition the sludge before dewatering. These polymers have high cost rendering the mechanical dewatering uneconomical.

It is possible to handle more thickened and dewatered sludge by adding polymer and initial cost of this system is lower than ozonation system. Howewer it was found that ozonation had same effect and it would be more economical than polymer system after 11 years.
\end{abstract}

Keywords: Sludge thickening, Foam filtration, Sludge ozonation, Sludge dewatering, Cost of Ozonation 


\section{GİRIS}

Atık sulardan kaynaklanan çamurların uzaklaştırılması atıksu mühendisliği sahasının en zor ve en pahalı problemi olmaya devam etmektedir. Atıksu arıtma tesisleri, kullanılan sisteme göre ön çöktürme çamuru, aktif çamur, kimyasal çamur veya anaerobik çamur gibi farklı çamurlar üretmektedir. Bu artık çamurlar, uzaklaştırılmadan önce hacimlerinin azaltılması ve stabilize hale getirilmesi gibi işlemlere tabi tutulmak zorundadırlar. Bunun için genellikle kullanılan yöntemler koşullandırmayla birleştirilmiş yoğunlaştırma ve susuzlaştırmadır.

Atıksu arıtımı yüksek miktarda çamur oluşumuyla beraber, oluşan bu çamurun tesisten uzaklaştırılması için ciddi maliyet artışlarını da beraberinde getirir. Fazla çamurun arıtımı ve bertarafi arıtma tesisi işletme maliyetinin \%50 hatta \%60'ını kapsamaktadır. Avrupa'da 2005 yılında elde edilen verilere göre arıtma tesislerinden kaynaklanan fazla çamur miktarı 10 milyar kg'a ulaşmıştır. $\mathrm{Bu}$ da yeni regülasyonlarla inşa edilen yeni arıtma tesislerinden kaynaklanmaktadır [1].

Çamur yoğunlaştırmada kullanılan yöntemlerin başında cazibeli yoğunlaştırıcılar gelmektedir. Buna ilaveten cazibeli kayışlı yoğunlaştırıcılar ve çözünmüş hava flotasyonu da kullanılan yoğunlaştırma yöntemlerindendir. Bu tip yoğunlaştırıcıların ilk yatırım maliyetleri düşük olsa da büyük alan kaplamak gibi dezavantajları vardır.

Sünger filtre ile çamurun yoğunlaştırılması yeni ve alternatif bir teknik olup küçük ölçekli arıtma tesisleri için idealdir. Bu çalışmada sünger filtre ile çamur yoğunlaştırmada ozonun etkisi araştırılmıştır ve maliyet analizi yapılmıştır.

\section{MATERYAL VE YÖNTEM}

\section{1.Çamur}

Bu çalışmada kullanılan çamur numuneleri İstanbul Paşaköy İleri Biyolojik Atıksu Arıtma tesisinin geri devir hattından düzenli olarak her hafta alınmış ve Marmara Üniversitesi Çevre Mühendisliği laboratuvarına 30 litrelik bidonlarla gönderilmiştir.

\section{Polieter sünger}

Yapılan bu çalışmada polieter sünger filtre yoğunlaştırıcı materyal olarak kullanılmış olup bu filtre yumuşak, sıkıştırılabilir ve ucuz bir maddedir. Düzenli aralıklarda olmayan gözenek boyutları 200-250 $\mu$ m'dir. Geri devir çamuru filtre düzeneğine ham olarak ya da değişen ozon dozajları ile sabit debide beslenmiştir. Yoğunlaştırma performansı çamur kekindeki toplam katı madde miktarı analizi ile belirlenmiştir. Filtrat kalitesi değişen ozon konsantrasyonlarına göre analiz edilmiştir. Çamur susuzlaştırma için ise CST (kapiler emme zamanı) değerleri ölçülmüş ve sonuçlar belirlenmiştir. 


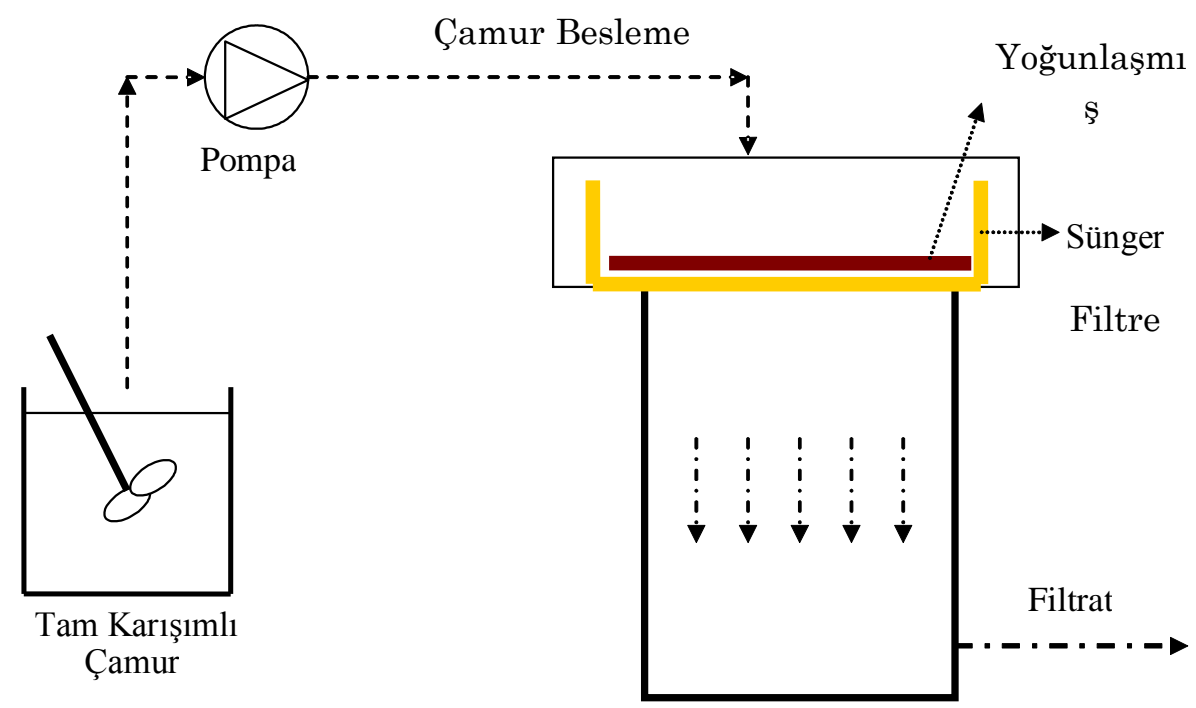

Şekil 1. Laboratuvar düzeneğinin şematik görünüşü

\section{3.Çamurun Ozonlanması}

Oksijen beslemeli PCI model GL-1 tip ozon jeneratörü çamur ozonlanması için kullanılmıştır. Ozon seramik difüzör ile çamura enjekte edilmiştir. Tüm borular teflondur. Dakikada 787.5 mg ozonu \%100 kapasitede üretebilen bu cihaz ile \%5 lik çıkış ile 4 scfh oksijen debisi uygulanmıştır. Verilecek ozon miktarı çamurun ozonlanma süresiyle ayarlanmıştır. Örneğin $20 \mathrm{mg} \mathrm{O}_{3} / \mathrm{AKM}$ verilmek istendiğinde ozonlama suresi 16,2 dakika olarak bulunmuştur. Aşağıdaki hesaba göre ozonlama yapılmıştır.

$$
20 \frac{m g}{l} \text { ozon }=\left(787.5 m g \frac{O 3}{d a k}\right) *\left(\frac{4}{32} S C F H\right) *\left(\frac{5}{100}\right) *\left(\frac{X d a k}{4 \mathrm{l}}\right)
$$

$\mathrm{SCHF}=$ standart $\mathrm{ft}^{3} / \mathrm{saat}$

\section{Analizler}

Yapılan bu çalışmada KOİ, AKM, TKM ve CST ölçümleri yapılmıştır. Bütün analizler Su ve Atık suların Analizi için Standard Metotlar (21.baskı) [2] kitabında belirtildiği şekilde yapılmıştır.

\section{Yoğunlaştırma Prosedürü}

Polieter sünger $40 \mathrm{~cm}$ x 40cm'lik standın üzerine yerleştirilmiştir. Stant fiberglas tank üzerine oturtulmuştur. Peristaltik pompa ile ham çamur tam karışımlı olarak sisteme beslenmiştir. Her deney toplamda 105 dakikadan oluşturulmuştur. İlk 30 dakika beslemeyi 15 dakika drenaj süresi ve ikinci 30 dakika beslemeyi, 30 dakika drenaj süresi izlemiştir. Filtre üzerinde oluşan çamur kekinden 15 dakikada bir çamur numunesi alınarak TKM ölçümleri yapılmıştır. Süzüntü suyu ise tankta biriktirildikten sonra KOİ ve TKM analizleri için 100 ml'lik numune kaplarına alınmış ve hemen ölçümleri yapılmıştır. 


\section{Hesaplamalar}

Çamur hesabı aşağıdaki belirtilenlere göre yapılmıştır.

\section{1.Çamur Miktarı}

$\mathrm{Bu}$ çalışmanın maliyet analizi 1.000 ve 100.000 kişilik iki ayrı arıtma tesisi için hesaplanmıştır.

Bir kişi için günlük atıksu miktarı 250 litre olarak öngörülmüş ve arıtma tesisi prosesinin uzun havalandırma olacağı varsayılmıştır. Bu duruma göre 1.000 kişilik arıtma tesisinden çıkan atık çamur miktarı yaklaşı $6,2 \mathrm{~m}^{3} /$ gün, 100.000 kişilik tesis için atık çamur miktarı ise yaklaşık $620 \mathrm{~m}^{3} /$ gün olarak hesaplanmıştır.

\section{BULGULAR VE TARTIŞMA}

Materyal ve yöntem bölümünde belirtilen prosedür tüm çalışma boyunca değişik ozon dozajlarıyla 3'er set olarak tekrar edilmiş ve bu değerlerin ortalama verileri üzerinden varılan sonuçlar aşağıda belirtilmiştir.

\section{Yoğunlaştırmada Ozonun Etkisi}

Ozon konsantrasyonu 5-30 mg $\mathrm{O}_{3} / \mathrm{g}$ AKM olarak uygulanmıştır ve Tablo 1'de çamur hacim değişiklikleri verilmiştir.

Tablo 1. Değişik ozon dozajlarına göre azalan çamur hacimleri

\begin{tabular}{|c|c|c|c|c|}
\hline Ozone Dozajı & Durum & $\begin{array}{c}\text { Başlangıç } \\
\text { Katı Madde } \\
(\%)\end{array}$ & $\begin{array}{c}\text { Son Katı } \\
\text { Madde } \\
(\%)\end{array}$ & $\begin{array}{c}\text { Çamur Hacim } \\
\text { Azalması } \\
(\%)\end{array}$ \\
\hline \multirow[b]{2}{*}{$5 \mathrm{mg} \mathrm{O} / \mathrm{g} A K M$} & Ham çamur & 0,31 & 8,31 & 96,26 \\
\hline & $\begin{array}{l}\text { Ozonlu } \\
\text { çamur* }\end{array}$ & 0,67 & 8,06 & 91,68 \\
\hline \multirow[b]{2}{*}{$10 \mathrm{mg} \mathrm{O} / \mathrm{g} A K M$} & Ham çamur & $\mathbf{0 , 8 7}$ & 8,40 & 89,64 \\
\hline & $\begin{array}{l}\text { Ozonlu } \\
\text { çamur* }\end{array}$ & 0,34 & 8,55 & 96,02 \\
\hline \multirow[b]{2}{*}{$15 \mathrm{mg} \mathrm{O}_{3} / \mathrm{g} \mathrm{AKM}$} & Ham çamur & 0,42 & 6,57 & 93,60 \\
\hline & $\begin{array}{l}\text { Ozonlu } \\
\text { çamur* }\end{array}$ & 0,71 & 6,87 & 89,66 \\
\hline \multirow[b]{2}{*}{$20 \mathrm{mg} \mathrm{O}_{3} / \mathrm{g} \mathrm{AKM}$} & Ham çamur & 1,37 & 7,89 & 82,64 \\
\hline & $\begin{array}{l}\text { Ozonlu } \\
\text { çamur* }\end{array}$ & 1,31 & 6,92 & 81,07 \\
\hline \multirow[b]{2}{*}{$25 \mathrm{mg} \mathrm{O}_{3} / \mathrm{g} \mathrm{AKM}$} & Ham çamur & 1,37 & 7,89 & 82,64 \\
\hline & $\begin{array}{l}\text { Ozonlu } \\
\text { çamur* }\end{array}$ & 1,49 & 7,43 & 79,95 \\
\hline \multirow[b]{2}{*}{$30 \mathrm{mg} \mathrm{O}_{3} / \mathrm{g} \mathrm{AKM}$} & Ham çamur & 1,37 & 7,89 & 82,64 \\
\hline & $\begin{array}{l}\text { Ozonlu } \\
\text { çamur* }\end{array}$ & 1,35 & 5,91 & 77,16 \\
\hline
\end{tabular}


* Başlangıç katı madde değerleri, çamur ozonlanmadan önceki değerlerdir. Bu değerler belirlendikten sonra, AKM miktarına göre ozonlama yapılmıştır.

Başlangıç katı madde yüzdeleri \%0,31 ile \%1,49 arasında değişmektedir. Filtre üzerindeki son katı madde konsantrasyonu maksimum \%8,55 olarak bulunmuş, ozonsuz çamurlarda ise $\% 8,40$ olarak hesaplanmıştır. Çamur hacim azalmaları \%77,16 ile \%96,26 arasında bulunmuştur. Ham çamur hacim azalması minimum hacim azalması \%82,64 maksimum \%96,26 olarak hesaplanmıştır. Ozonlu çamurlarda ise bu değer minimum \%77,16, maksimum \%96,02 olarak bulunmuştur. Tablo 1'de de görüldüğü gibi optimum ozon dozaj1 $10 \mathrm{mg} \mathrm{O} / \mathrm{g}$ AKM olarak belirlenmiştir. Bu karşılaştırma yapılırken azalan çamur hacimleri göz önünde bulundurularak yapılmıştır. $10 \mathrm{mg} \mathrm{O}_{3} / \mathrm{g}$ AKM dosajından sonra ozonun çamurun yoğunlaştırılması üzerinde pozitif bir etkisi olmadığı görülmüştür. Hücrelerin parçalanması için gerekli minimum ozon konsantrasyonu sağlanmadığı sürece çamurun üzerinde bir etkisi olmayacağ1, 0,02 $\mathrm{g} \mathrm{O}_{3} / \mathrm{g}$ TKM dosajından sonra hücre yapısında bozulmaların başlayacağ $0,05 \mathrm{~g} \mathrm{O}_{3} / \mathrm{AKM}$ dosajına kadar çözünmüş KOİ miktarının artacağı, bu dosajdan sonra fazladan ozonlamanın bir etkisi olmadığı literatürde bildirilmiştir [3].

$\mathrm{Bu}$ çalışma ozonlamanın çamur yoğunlaştırma üzerindeki etkisi bakımından özgün bir çalışma olması sebebiyle literatürde karşılaştırılacak herhangi bir değer bulunmamaktadır.

\section{Ozonun Susuzlaştırma Üzerindeki Etkisi}

Yapılan CST (kapiler emme zamanı) analizlerine göre ozonun susuzlaştırma üzerinde ciddi bir etkisi görülmemiş olup sadece $20 \mathrm{mg} \mathrm{O} / \mathrm{g}$ AKM dozajında CST değerlerinde azalma görülmüştür. Yapılan çalışmada çamurun ozonlanmadan önce ve ozonlandıktan sonra ölçülen CST değerleri Tablo 2'de verilmiştir.

Tablo 2. Çamur CST Değerleri

\begin{tabular}{|c|c|c|c|}
\hline Ozon dosajı & Durum & CST değeri (saniye) & Ozon etkisi \\
\hline \multirow{2}{*}{$5 \mathrm{mg} \mathrm{O}_{3} / \mathrm{g} \mathrm{AKM}$} & Ham çamur & 36,6 & \multirow{2}{*}{ Olumsuz } \\
\hline & Ozonlanmış çamur & 236,2 & \\
\hline \multirow[b]{2}{*}{$10 \mathrm{mg} \mathrm{O}_{3} / \mathrm{g} \mathrm{AKM}$} & Ham çamur & 247,6 & \multirow[b]{2}{*}{ Olumsuz } \\
\hline & Ozonlanmış çamur & 511,6 & \\
\hline \multirow{2}{*}{$15 \mathrm{mg} \mathrm{O} / \mathrm{g} \mathrm{AKM}$} & Ham çamur & 110,7 & \multirow{2}{*}{ Olumsuz } \\
\hline & Ozonlanmış çamur & 127,2 & \\
\hline \multirow[b]{2}{*}{$20 \mathrm{mg} \mathrm{O} / \mathrm{g} A K M$} & Ham çamur & 58,6 & \multirow{2}{*}{ Olumlu } \\
\hline & Ozonlanmış çamur & 45,3 & \\
\hline \multirow{2}{*}{$25 \mathrm{mg} \mathrm{O}_{3} / \mathrm{g} \mathrm{AKM}$} & Ham çamur & 58,6 & \multirow[b]{2}{*}{ Olumsuz } \\
\hline & Ozonlanmış çamur & 100,6 & \\
\hline \multirow{2}{*}{$30 \mathrm{mg} \mathrm{O}_{3} / \mathrm{g} \mathrm{AKM}$} & Ham çamur & 58,6 & \multirow{2}{*}{ Olumsuz } \\
\hline & Ozonlanmış çamur & 83,2 & \\
\hline
\end{tabular}


Çamuru ozonlamanın susuzlaştırma üzerinde zayıf bir etkisi olduğu gözlemlenmiştir. Genellikle olumsuz yönde etkilenen susuzlaştırma için optimum dozaj bu çalışmaya göre 20 mg $\mathrm{O}_{3} / \mathrm{g}$ AKM olarak belirlenmiştir. Ham çamur değerlerinde farklı CST değerlerinin ölçülmesinin sebebi, numunelerin haftalık olarak atıksu arıtma tesisinden getirilmesi ve tesisteki günlük farklılıkların numunelere yansıması yüzünden kaynaklanmıştır.

Bougrier (2006) yaptığı çalışmada çamuru ozonlamanın CST değerini ciddi bir şekilde artırdığını söylemiş ki bu da ozonlamanın susuzlaştırma için uygun olmadığını göstermektedir [4]. Erden ve arkadaşlarının 2010 yılında yaptığı çalışmada da CST değerlerine bağlı olarak ozon oksidasyonunun çamur filtrasyonu üzerinde önemli bir etkiye sahip olmadığ 1 görülmüştür [5]. Braguglia ve arkadaşları (2012) ozonlamadan sonra CST değerlerinde hafif bir artış gözlemlemişlerdir [3].

\section{Ozonun Filtrat Üzerindeki Etkisi}

Yapılan çalışmada filtratta KOİ ve AKM değerleri ölçülmüştür. Yapılan çalışmalarda elde edilen değerler Tablo 3 'te verilmiştir.

Tablo 3. KOİ ve AKM ölçüm sonuçları

\begin{tabular}{|l|l|c|c|l|c|c|}
\hline \multirow{2}{*}{$\begin{array}{l}\text { Debi } \\
\text { (ml/dak) }\end{array}$} & $\begin{array}{l}\text { Ham } \\
\text { Çamur }\end{array}$ & $\begin{array}{c}\text { Filtrat } \\
\text { (ozonlanmamış) }\end{array}$ & $\begin{array}{c}\text { Filtrat } \\
\text { (ozonlanmış) }\end{array}$ & $\begin{array}{l}\text { Ham } \\
\text { Çamur }\end{array}$ & $\begin{array}{c}\text { Filtrat } \\
\text { (ozonlanmamış) }\end{array}$ & $\begin{array}{c}\text { Filtrat } \\
\text { (ozonlanmış) }\end{array}$ \\
\hline 20 & 13280 & 54 & 24 & 11500 & 234 & 290 \\
\hline 40 & 12440 & 24 & 18 & 9950 & 172 & 208 \\
\hline 60 & 13230 & 188 & 28 & 11200 & 147 & 452 \\
\hline 80 & 13930 & 78 & 38 & 19200 & 66 & 75 \\
\hline 100 & 12540 & 48 & 22 & 17600 & 84 & 119 \\
\hline 120 & 14130 & 72 & 34 & 10900 & 17 & 65 \\
\hline 140 & 13780 & 30 & 18 & 12400 & 65 & 202 \\
\hline
\end{tabular}

Tablo 3'te verilen değerlerden de görüleceği üzere ozonlama hücre parçalanmasına bağlı olarak KOİ değerlerini arttırmış, öte yandan AKM değerlerini azaltımıştır.

KOİ değerlerinin artmasının sebebi çamur ozonlandıktan sonra çamurun içinde bulunan mikroorganizmaların hücrelerinin parçalanmış olmasıdır. Hücre içeriği ortama karışmış ve buna bağlı olarak ortamdaki çözünmüş KOİ konsantrasyonu artmıştır. Hücrelerin parçalanması sonucu ham çamurda bulunan uçucu askıda katı madde miktarı (UAKM) azalmış ve dolayısıyla filtrattaki AKM değerleri de düşmüştür. Elde edilen bu sonuçlar literatürdeki verilerle uygunluk göstermektedir. Örneğin Manterola (2008) çalışmasında çamur ozonlanınca hücre parçalanması ve buna bağlı olarak KOİ değerlerinde artış olduğunu söylemiştir [6]. Zhang ve arkadaşlarının (2008) yaptıkları çalışmada çamurun ozonlanması sonucunda hücre parçalanmasını takiben bulundukları ortamda organik madde konsantrasyonun arttığ1 gözlemlemişlerdir [7]. Braguglia ve arkadaşları (2012) çamurun ozonlandıktan sonra UAKM ve buna bağlı olarak AKM değerlerinin \%27-34 arası azaldığını bildirmişlerdir [3]. He ve arkadaşlarının (2006) yaptıkları çalışmada çamur ozonlandıktan sonra UAKM değerleri yaklaşık \%25, AKM değerleri ise \%67 civarında azalmıştır. Yapılan değerlendirmede UAKM/AKM oranının ise 0,9 'dan 0,74 'e düştüğü gözlenmiştir [8]. Ayrıca elde edilen filtrat değerleri Tablo 4'te verilen İSKİ kanala deşarj limitleriyle karşılaştırılmıştır. 
Tablo 4. İSKİ Kanala Deşarj Limitleri [9]

\begin{tabular}{|c|c|c|}
\hline Parametre & $\begin{array}{c}\text { Tam Arıtma ile } \\
\text { Sonuçlanan Uygulamalar }\end{array}$ & $\begin{array}{l}\text { Derin Deniz Deşarji ile } \\
\text { Sonuçlanan Uygulamalar }\end{array}$ \\
\hline AKM(mg/l) & 500 & 350 \\
\hline KOİ(mg/l) & 1000 & 600 \\
\hline
\end{tabular}

Tablo 4'te görüldüğü gibi tüm değerlerin İSKİ kanala deşarj limitlerini sağlayabildiği anlaşılmıştır. Filtrattaki değerlerin kanala deşarj limitlerinden yüksek çıkması durumunda bu atıksuların tesisin başına geri döndürülmesi gerekmektedir. $\mathrm{Bu}$ da tesise ilave yük ve maliyettir.

\section{Maliyet Analizi}

Hesaplamalar 1.000 ve 100.000 kişilik iki ayrı tesis için yapılmış olup ozonlu sistem ile polimer ilaveli yoğunlaştırma/susuzlaştırma sistemi ile karşılaştırılmıştır. Bu karşılaştırmanın sonuçları Tablo 5'te verilmiştir.

Tablo 5. Maliyet Analizi

\begin{tabular}{|l|c|c|c|}
\hline $\begin{array}{l}\text { 1.000 Kişilik Arıtma } \\
\text { Tesisi }\end{array}$ & İlk Yatırım Maliyeti & $\begin{array}{c}\text { İşletme Maliyeti } \\
\text { (yıllık) }\end{array}$ & TOPLAM (Euro) \\
\hline Ozon sistemi & 22.500 & 358 & 22.858 \\
\hline Polimer sistemi & - & 254,7 & - \\
\hline $\begin{array}{l}\text { 100.000 Kişilik } \\
\text { Arıtma Tesisi }\end{array}$ & İlk Yatırım Maliyeti & $\begin{array}{c}\text { İşletme Maliyeti } \\
\text { (yıllık) }\end{array}$ & TOPLAM (Euro) \\
\hline Ozon sistemi & 176.250 & 9.002 & 185.252 \\
\hline Polimer sistemi & 4.980 & 25.470 & 30.450 \\
\hline
\end{tabular}

Tablo 5'ten çıkan sonuçlara göre 11 yıl sonunda ozonlu sistem polimer kullanılan sisteme göre daha ekonomik olacaktır. İşletme maliyetleri $10 \mathrm{mg} \mathrm{O} / \mathrm{g} A K M$ dozajı baz alınarak hesaplanmıştır. Polimer ihtiyacının ise $1 \mathrm{mg} / 1$ olacağı varsayılmıştır. İşletme maliyetleri sadece enerji, bakım-onarım ve kimyasal madde toplamları olarak hesaplanmış olup diğer işletme maliyetleri göz önünde bulundurulmamıştır.

\section{Sonuç}

$\mathrm{Bu}$ çalışmada ozonlamanın çamur yoğunlaştırma ve susuzlaştırmadaki etkisi araştırılmış ayrıca filtrat değerleri de göz önüne alınmıştır.

Bulunan sonuçlara göre ise $10 \mathrm{mg} \mathrm{O} 3 / \mathrm{g}$ AKM dozajı yoğunlaştırma için optimum dozaj olarak bulunmuştur. Diğer taraftan ozonun susuzlaştırma üzerinde tamamen pozitif bir etkisi olmadığ1 görülmüş sadece $20 \mathrm{mg} \mathrm{O} / \mathrm{g}$ AKM dozajında susuzlaştırmanın azda olsa arttığ1 belirlenmiştir. 
Ozonlamadan sonra oluşan filtrattaki KOİ değerlerinin arttığı, AKM değerlerinin ise azaldı̆̆ı görülmüştür. Filtrat kalitesinin İSKİ deşarj limitlerinin altında olduğu ölçülmüştür.

Yapılan hesaplamalar ve maliyet analizlerinde görülen değerlere bağlı olarak da yaklaşık 10 y1l sonra ozonlama sisteminin klasik polimer ilave sisteminden daha ekonomik olacağ 1 Sonucuna Varılmıştır.

\section{Teşekkür}

$\mathrm{Bu}$ çalışmada bizlere değerli yardımlarını esirgemeyen Çevre Mühendisliği Bölümü laboratuvarının değerli çalışanları ve Doç.Dr.Kozet YAPSAKLI'ya teşekkürü borç biliriz.

\section{KAYNAKLAR}

[1] Campos J.L., Otero L., Franco A., Mosquera-Corral A., Roca E. (2009). Ozonation strategies to reduce sludge production of a seafood industry WWTP, Bioresource Technology, 100 (3), 1069-1073.

[2] Standard Methods for the Examination of Water and Wastewater, 2005. APHA, AWWA, WEF, 21. Edition, Washington, D.C.

[3] Braguglia C.M., Gianico A., Mininni G. (2012). Comparison between ozone and ultrasound disintegration on sludge anaerobic digestion. Journal of Environmental Management, 95, 139-143.

[4] Bougrier C., Albasi C., Delgen`es J.P., Carr`ere H. (2007). Impacts of thermal pretreatments on the semi-continuous anaerobic digestion of waste activated sludge. Biochemical Engineering Journal, 34 (1), 20-27.

[5] Erden G., Demir O., Filibeli A. (2010). Disintegration of biological sludge: Effect of ozone oxidation and ultrasonic treatment on aerobic digestibility. Bioresource Technology, 101 (21), 8093-8098

[6] Manterola G., Uriarte I., Sanchoa L. (2008). The effect of operational parameters of the process of sludge ozonation on the solubilisation of organic and nitrogenous compounds. Water Research, 42 (12), 3191-3197

[7] Zhang G , Jing Y, Huanzhi L, Jie Z. (2008). Sludge ozonation: Disintegration, supernatant changes and mechanisms. Bioresource Technology, 99 (18), 9029-9031.

[8] He S.B., Xue G., Wang B.Z. (2006). Activated sludge ozonation to reduce sludge production in membrane bioreactor (MBR). Journal of Hazardous Materials, 135, 406411.

[9] İSKİ Atıksuların Kanalizasyona Deşarj Yönetmeliği, 2007, Tablo 1. 